\title{
DEFORMAÇÃO DA LITERATURA
}

BRASILEIRA

Rafael Otávio Fares Ferreira*

RESUMO: Este ensaio-manifesto busca colocar algumas questões relativas aos textos que tem sido publicados, principalmente por povos indígenas, e não são entendidos como literatura pelas universidades, nem tampouco são lidos, apesar da lei $11.645 \mathrm{de}$ março de 2008 que estabelece que é obrigatório o ensino de culturas indígenas e africanas no Brasil. $\mathrm{O}$ argumento para o texto é retirado da palestra $A$ literatura brasileira da perspectiva pós - colonial feita por Silviano Santiago que afirma que a literatura brasileira já está formada e é preciso desconstruí-la, ampliando a inserção de outros textos que não os do sistema já consagrado.

PALAVRAS-CHAVE: Literatura Brasileira, Mito, Perspectiva, Culturas Indígenas, Culturas Afro-Brasileiras.
* rafaelotavio@hotmail.com

Doutorando em Teoria da Literatura pelo Pós-Lit, na Faculdade de Letras da UFMG. Também cursou o mestrado na mesma instiuição com a dissertação: Esta é a paisagem que o pensamento permite:
textualidades indígenas.

RESUMEN: Este texto ensayístico-manifiesto busca poner algunas preguntas con respecto a los textos que se han publicado, principalmente por los pueblos indígenas, y que los estudiosos no comprenden como literatura en las universidades, o se leen, a pesar de la ley 11.645 del mes de marzo de 2008, establece que es obligatorio para enseñar culturas indígenas y africanos en Brasil. El argumento para el texto está tomado de la literatura brasileña conferencia de la perspectiva poscolonial hecha por Silviano Santiago, que establece que la literatura brasileña a está formado y tenemos que deconstruir, la ampliación de la inclusión de otros textos que las del sistema ya establecido.

PALABRAS CLAVE: Literatura brasileña, el mito, la perspectiva, las culturas indígenas, culturas afro-brasileños. 
1. CANDIDO, Antonio. Formação da literatura brasileira: momento decisivos, p.28.

2. Palestra ministrada por Silviano Santiago na Faculdade de Letras denominada $A$ literatura brasileira da perspectiva póscolonial - um depoimento em 10 de março de 2016
Só me interessa o que não é meu

(Manifesto Antropófago)

A chamada literatura brasileira tem em sua construção momentos consagrados como os descritos no livro de Antonio Candido Formação da Literatura Brasileira, sob a égide de discursos do tipo "ela é ramo da literatura portuguesa":

A nossa literatura é ramo da portuguesa; pode-se considerá-la independente desde Gregório de Matos ou só após Gonçalves Dias e José de Alencar, segundo a perspectiva adotada. No presente livro, a atenção se volta para o início de uma literatura propriamente dita, como fenômeno de civilização, não algo necessariamente diverso da portuguesa. Elas se unem tão intimamente, em todo o caso, até meados do século XIX que utilizo em mais de um passo, para indicar este fato, a expressão "literatura comum"(brasileira e portuguesa). ${ }^{1}$

Como muito bem formulou o crítico Silviano Santiago ${ }^{2}$, citando o próprio Formação da Literatura Brasileira além de outros livros como Minha Formação de Joaquim Nabuco e Formação do Brasil contemporâneo de Caio Prado Jr., o século XX teve o papel de ser formativo para o brasileiro. O crítico então aposta que agora, no século XXI, a literatura brasileira necessita avançar para outra fase: a inserção, desconstruindo o que já está formado:
É preciso pensar profundamente esse campo semântico, que está em aberto, propor outro paradigma. Que precisa ser pensado em literatura, em economia, em política, em sociologia. Neste século 21, precisamos fazer com o conceito de 'inserção' o que Antonio Candido fez com o de 'formação' no século $20{ }^{3}$

Como o próprio Silviano denunciou, este sistema literário formado tem em sua constituição uma perspectiva eurocentrista. Mas, como lambe gramaticalmente o chão da paisagem, mapa-múndi Brasil, possui seus desvios antropofágicos em relação ao movimento desta tendência, demarcando o que crítico nomeou de seu entre-lugar de 1971, não só se referindo ao Brasil, mas sim a toda a literatura latino-americana:

Entre o sacrifício e o jogo, entre a prisão e a transgressão, entre a submissão ao código e a agressão, entre a obediência e a rebelião, entre a assimilação e a expressão - ali, nesse lugar aparentemente vazio, seu templo e seu lugar de clandestinidade, ali, se realiza o ritual antropófago da literatura latino-americana. ${ }^{4}$

O Brasil tornou-se reconhecível no século XX. Samba, futebol, Amazônia, favela, novela, corrupção e a figura do Lula são imagens, matéria de narrativas universais. Um país sem dúvida formado com identidade forte. Um país que conta com uma literatura: narrativas canônicas, representantes dos estilos de época ocidentais e toda uma gama de entre-lugares
3. CANDIDO. Entrevista, março de 2015. Disponivel em https://www. ufmg.br/online/arquivos/037483. shtml, acessado em setembro de 2016

4. SANTIAGO. Uma literatura nos trópicos: ensaios sobre dependência cultural p. 26.
EM TESE
BELO HORIZONTE
v. 22
N. 2
MAIO-AGO. 2016
FERREIRA. Deformação da literatura brasileira
P. $54-63$ 
sobreimpressos com as várias grandes correntes literárias do mundo ocidental. Um país com uma prática-teórica que não deixa a desejar: a antropofagia, a deglutição das culturas formuladas pelo predador Oswald de Andrade.

Este texto poderia percorrer a literatura brasileira em todo o século XX, porém, é necessário que se vá direto ao ponto: é preciso deformar esta tradição formada, cristalizada pela historiografia oficial/escolar e de nome Literatura Brasileira. Descolonizar, ir além do entre-lugar. Deformação que poderia se dar com literaturas menores que promovem a experiência concreta de sairmos do também paralisadocidente. Há um movimento de edições e literaturas marginais que já criam fortes desestabilizações. Mas quero aqui chamar a atenção para as diversas mitologias indígenas e africanas, que têm sido cada vez mais escritas e publicadas pelos pró prios membros destas comunidades. Florescem abrindo caminhos que multiplicam, reinventam o trilho, ou os trilhos, desta formada literatura brasileira.

Como rios subterrâneos caudalosos, arrastam, criam erosões, desfazem territórios tão consagrados e nos fazem questionar por que não são lidos os livros que se formaram nestas paisagens. Histórias de onça, histórias de formigas, histórias das árvores, histórias de cipós, histórias de contato, histórias de violência, histórias das entidades espirituais e dos mais diversos rios. Eles que elaboram, tornam em sensação, como formulado por Fernando Pessoa ${ }^{5}$ : todo estado de alma é uma paisagem. Fazem texto de pensamentos do que há de mais concreto na terra dos pau-brasis. Somos concretistas. Assim como não foi dada a devida atenção às águas tão abundantes, das nascentes aos olhos d ägua, e estão secando, as textualidades extra-ocidentais, estas belíssimas paisagens, vitais para seus povos, não receberam o devido valor, ou a devida leitura

A ampliação do comparativismo literário, onde a base original da comparação foi sempre européia, ocidental, ganha matrizes originárias e múltiplas nas diversas cosmogonias dos povos Maxakali, Pataxó, Yanomâmi, Dessana, Ticuna, Xacriabá, Crenac, Huni Kuin e assim por diante, somando mais de 200 etnias, que tem traduzido suas narrativas em escrita alfabética nos últimos anos ${ }^{6}$. Que experiência fantástica é ler o Macunaíma de Mário de Andrade a partir das obras de Jaider Esbell, artista indígena Macuxi de Roraima. Os Macuxi com sua Odisséia Homérica. Mário de Andrade com seu Ulisses Joyciano. Nestas textualidades residem leituras de outros mundos possíveis onde podemos, inclusive, questionar até onde vai o território do mapa-múndi Brasil. E por que não da América com um todo? Os Huni Kuin estão tanto no Brasil quanto no Peru. Publicaram um livro bilingue belíssimo que é o Shenipapu Miyui, com diversas narrativas de seu povo. Falam tanto português como o espanhol, mas sua língua materna é o hãtxa kuin. Quantos devires indígenas como este suportará a denominação Brasil?
5. Fernando Pessoa, na abertura de livro Cancioneiro, escreve: toda estado de alma é uma paisagem. E mais do que isso, que as paisagens se interseccionam. Entendo com ele, que todas as sensações podem ser descritas como paisagens. E estas nos formam constantemente. Ver também o movimento criado por ele: o sensacionismo.

6. Não que eles já não tivessem uma escrita. Talvez não uma escrita alfabética. Sobre esta discussão sugiro a leitura dissertação Esta é a paisagem que o pensamento parmite: que o pensamento permite: 
7. A professora Maria Inês de Almeida é uma das criadoras do FIEI - UFMG, Curso Intercultural para Formação de Educadores Indígenas e coordenadora do núcleo de pesquisas Literaterras. As pesquisas a que me refiro são O livro indígena e suas múltiplas grafias (mestrado) e $A$ literatura indígena nas editoras brasileiras (monografia).

8. Os livros também estão sendo disponibilizados pelo site: http:// www.letras.ufmg.br/indigena/
Em duas pesquisas realizadas na Faculdade de Letras da UFMG, ambas sob a orientação da professora Maria Inês de Almeida ${ }^{7}$, foram contabilizados quase mil livros indígenas publicados nos últimos trinta anos no Brasil, entre livros de autoria individual, editados na maioria das vezes por editoras comercias e livros de autoria coletiva, normalmente feitos por entidades públicas. Isso sem falar nos outros que foram publicados em outros países americanos. De todos os países poderíamos citar centenas também confeccionados nos últimos anos.

Posso citar também a produção de grupos de pesquisa que vêm trabalhando nos mais diversos cursos de formação para professores indígenas nas universidades e a quantidade de monografias, dissertações e teses que têm sido publicadas pelos membros das mais variadas etnias, sobre os mais diversos conhecimentos. Só o Núcleo Literaterras da UFMG, através da SECADI - Secretaria de Educação Continuada, Diversidade, Alfabetização e Inclusão (de 2005 até 2014), participou da confecção de mais de uma centena de livros indígenas nas últimas décadas. Toda esta produção está disponível no acervo indígena que foi criado na biblioteca central da UFMG. ${ }^{8}$

Quantas não são as possibilidades teóricas e literárias que estes livros coletivos produzem? Como sabemos, a noção de autoria é relativamente nova para a história do ocidente, uma construção burguesa que já tem na arte contemporânea seus pilares abalados. Mais do que a "Morte do Autor" de Foucault, estes livros indígenas nos dão um exemplo vivo dos mananciais míticos de onde surgem os grandes rios imagéticos que chamamos narrativas. Livros que podem ser de autoria da Jibóia, como no caso do Huni Kuin, o que não pode se enquadrar no direito autoral como o conhecemos. E para pensar o mito, suas relações com a literatura e a história então. Verdadeiros poemas épicos com a grandeza e potência como todos os outros do mundo, vejamos o início deste contado pelos Dessana:

No princípio o mundo não existia. As trevas cobriam tudo Enquanto não havia nada, apareceu uma mulher por is mesma. Isso aconteceu no meio das trevas. Ela apareceu sustentando-se sobre o seu bando de quartzo branco. Enquanto estava aparecendo, ela cobriu-se com seus enfeites e fez como um quarto. Esse quarto chama-se Uhtãboho taribu, o "Quarto de Quartzo Branco". Ela se chamava Yebá Buró, a "Avó do Mundo" ou, também "Avó da Terra".

Que maravilha então se pensarmos a escrita junto do ponto de vista indígena? A escrita, com toda sua força semiótica dos rituais, cantos, pinturas corporais, adereços que em sentido amplo se confundindo com a própria paisagem. Escrita que se dá nas folhas das árvores, nas peles das cobras, ou nas pedras como explica o antropólogo Hugh-Jones, em consonância com a Gramatologia de Derrida:
9. KEHIRI; PÃRÕKUMU. Antes o mundo não existia, p. 19. 
10. HUGH-JONES. Escrita nas pedras, escritas no papel: palavras em imagens, p. 4
Exploro alguns dos sistemas de memória gráficos e não-graficos que servem de suporte para várias formas de história indígena ou "mitos" na região do Alto Rio Negro. São esses sistemas de memória que tenho em mente quando me refiro a escrita. Defendo que mito e escrita devem ser entendidos a partir do ponto de vista indígena. Também sugiro que, em vez de insistir na distinção rigorosa entre as sociedades com e sem escrita, ou de questionar se os petróglifos, pinturas nas paredes e nas cestarias e outras formas de inscrição são ou não "escrita verdadeiras", é mais interessante e produtivo ampliar o campo de pesquisa e investigar o quando as formas gráficas obvias e as arquiteturais e espaciais, aparentemente não-gráficas, agem conjuntamente com as tradições orais. ${ }^{10}$

O que de fato esses livros e mitos indígenas nos dão a ler são perspectivas outras, usando o termo de Viveiros de Castro. Conhecimentos múltiplos da paisagem brasilis. Outros mundos, outros países, outros devires. Perspectivismo pelo qual Guimarães Rosa passeou nas suas "Conversas de Bois", "Meu tio o Iauaretê" e em tantas outras passagens. Não sem moti vo, um livro brilhante neste sentido é o Um peixe olhou olhou pra mim, uma etnografia sobre o povo Yudjá, da antropóloga Tânia Stolze Lima:

A etnografia Wari' (Vilaça, 1992; Conklin, 2201a) oferece uma elaboração interessante que nos permite passar, por meio da ação humana tal como descrita pelos Yudjá, dos estados da subjetividade para as propriedades do cosmos. Sustentam as pessoas desse povo indígena de Rondônia que nós, os seres humanos, somos animais desta ou daquela espécie - segundo a espécie animal (aquelas que são ditas dotadas de espírito) que nos tem sob a sua perspectiva: o veado vê a gente tal como a gente o vê, e vê-se a si mesmo tal como a gente se vê. Entre os Yudjá, as pessoas descrevem algo razoavelmente distinto: enquanto nós, os seres humanos, vemos os animais como animais, eles se consideram gente, e nos consideram gente também, isto é, pessoas com quem poderiam mostrar desejo de se relacionar, visto que para os animais a nossa alteridade relativa com eles é humana, quer dizer, política. ${ }^{11}$

Guimarães adorava as perspectivas e seus conterrâneos, mineiros de dna indígena, sempre as adotaram. Manuelzão que o diga nos pontos de vista do sertão. As narrativas extra-ocidentais ganham uma rica possibilidade de leitura com a noção da perspectiva. Para os Maxakali uma das noções fundamentais para a vida é a de yãmiy. Yãmiy é canto, mas é também de uma maneira equivocada espírito mas também é forma. Quando morre a pessoa terá sua imagem transformada em yãmiy canto. Dentre os mais importantes está o yãmiy do morcego (xunim em maxakali), em seu ritual são entoados variados cantos, inclusive de outros yãmiy:
11. LIMA. Um peixe olhou pra mim p. 215 
Hoo aai
Hoo aai
Hoiaá

Xate hãm ãgnut punup Você vem para cantar

Tu anum yiãã Eu pensei que você vinha

Xate hnam ãgnut punup Você vem para cantar

Tu anum yiãã Eu pensei que você vinha

Nãg pape yikaok nã xaxip Ou você não vai

Nãg pape yikaok nã xaxip Ficar em pé parado e cantar alto Ou você não vai

Ficar em pé parado e cantar alto

Haiyak ooo hiai

Haiyak ooo hiai

Haiyak ooo hiai

Haiyak ooo hiai

Ou este da Zabelê cantado por Marinho Maxakali, um dos vários que serão cantados no ritual do morcego, já que ele o morcego é contará muito das histórias de cada um dos outros animais e de outros yamiys, como este que está no livro Cantos do Morcego e Hemex-espíritos ${ }^{12}$.
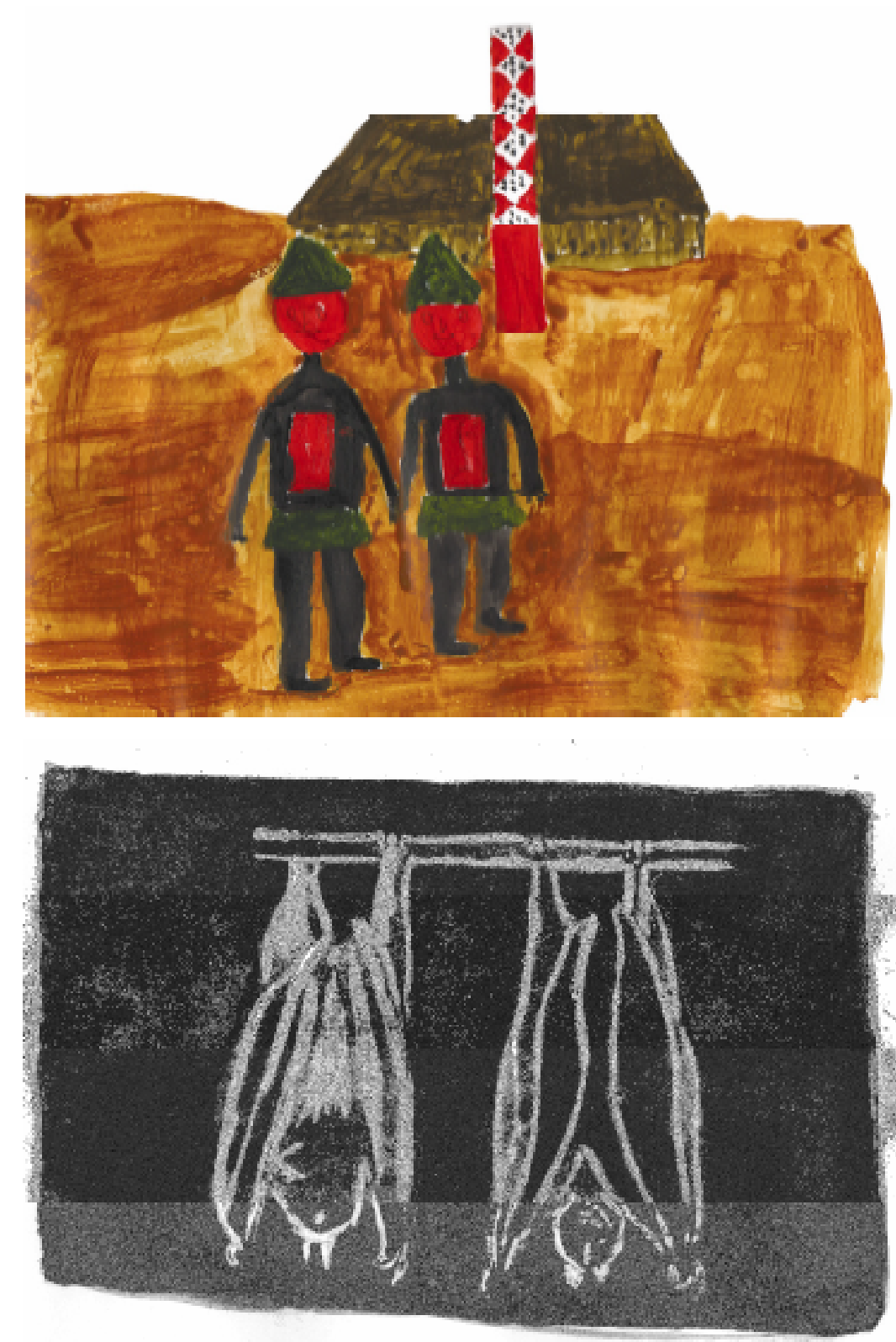

2. MAXAKALI et al. Cantos dos povos Morcego e Hemex-

espíritos.
EM TESE

BELO HORIZONTE

v. 22

N. 2

MAIO-AGO. 2016

FERREIRA. Deformação da literatura brasileira 


\section{Zabelê (Marinho Maxakali)}

diodioi diodioi

ô ô ô ô ô ô

ô ô ô ô

ê ô ê ô ê ô

ô ê ôi ô ê oi ô ê oi ô ê oi e ôi

vou-me embora, vou-me embora vou-me embora com saudade quando chegar, quando chegar vou deitar com saudade

ô ô ô ê ô

ô ô ô ô ô

ô ô ô ê ô

guê guê guê guê guê

a cauda do peixe pequeno fez

guê guê guê guê

minha imagem no olho

minha imagem no olho ouvindo

sobrinhas

olhem apenas ouvindo zabelê no vale para \& canta

zabelê na colina para \& canta

zabelê na encosta da colina para \& canta

zabelê no cume da colina para \& canta

zabelê na outra costa da colina para \& canta

zabelê na quebrada para \& canta

zabelê na caída da quebrada para \& canta

zabelê no outro lado do rio para \& canta

zabelê na ilha do meio do rio pra \& canta

zabelê no cupinzeiro para \& canta

zabelê em cima do cipó para \& canta

zabelê ao lado da árvore para \& canta

zabelê na árvore de fruto perfumado para \& canta

zabelê com sede desce à nascente \& canta

zabelê ao mato volta \& vai cantar

zabelê metido no mato vai cantar, cantar

ôôôôôêô

êôôôê̂ôêô

Em seus livros, os Maxakali tem publicado diversos rituais com seus respectivos cantos/animais/yamîy. Só nos livros que retratam os yãmiy do morcego são mais uma centena de cantos. Além do Xunim, os Maxakali já publicaram muitos outros livros. Só em um livro como o do Cantos e histórias 
do Gavião-espírito podemos conhecer uma grande quantidade deste material mito-poético-pictórico-musical.

E quanto à palavra literatura. Ela está ancorada onde? Nesta tradição eurocentrista que nos fala Silviano? O que seria ela no mundo indígena? Poderíamos falar de uma literatura indígena? Acredito que para muitas pessoas, a resposta seria não. Para estes, a literatura está restrita a uma representação, autoral, só possível para os próprios. Talvez não seja mesmo uma literatura o que fazem os indígenas ao escreverem suas histórias, mas uma cosmovisão, um texto nascente, um olho $\mathrm{d}$ ăgua. Talvez pois não estamos diante de textos para uma análise crítica, onde deduziríamos o sentido ou os sentidos da obra. Diante destas obras, grandes textos de gozo, nos restaria perguntar para onde queremos ir...

Este tipo de pergunta que vivenciaríamos na universidade somente em alguns momentos como, por exemplo, em estudos da mitologia grega. A bela, distante e tão libertadora mitologia grega. Mas também quando estamos diante de textos como o de Kafka. E já que estes tem seu espaço, por que não pensarmos uma disciplina de mitologia indígena ou africana nas universidades brasileiras? Ou mais que isso, um programa de aprofundamento, para além da noção de nação, na multiplicidade destas mitologias e línguas? Um salve para o francês Lévi-Strauss, professor da USP, escritor e bricoleur das Mitológicas.
É verdade, nós temos uma lei para o ensino destas "literaturas" africanas e indígenas nas escolas, a lei 11.645. Um avanço sim, uma ação afirmativa. E desde quando a lei foi a favor das sociedades contra o estado? Ouso dizer que as mitologias desses mais de duzentos povos são importantes textos que temos por essas paisagens. Estamos parados em Macunaíma até hoje? Em qual Macunaíma?

O dito da escritora portuguesa Maria Gabriela Llansol de que "não há literatura. Quando se escreve só importa saber em que real se entra e se há técnica adequada para abrir caminho a outros"13 flui para a deformação, para a desconstrução ou para a inserção de tantos textos que não entram no que chamamos literatura, mas enchem os olhos e os afetos dos que com eles estão. Então, não estamos tratando da literatura e sim dos pontos de vista, das perspectivas, das transcendentalições imanentes. São povos inteiros em plena transformação, em seus devires com as matas, os bichos e os recursos que a terra mãe provém. São visões de mundos invisíveis, de pluralidades de entidades divinas, múltiplas entradas nos cosmos. Possibilidades mitológicas na direção questionadora de Viveiros de Castro: "não se trata de discutir o sentido do mito, o mito é o sentido". Para cada um destes povos, estas narrativas são a própria Grande Saúde.

Oxalá as universidades sejam grandes terreiros ritualísticos onde desfilem pinturas corporais, línguas, danças, cantos, 
preces e mitos. Sejamos Yamiys, Orixás, Anjos e daimones. Yuxibus, Xapiripes, caboclos, nanocelulas. Não é possíve sair do eurocentrismo sentado, dentro das quatro paredes brancas; temos que inserir a floresta. Como diria Oswald: escola e a floresta. Acreditar nos sinais, nos instrumentos e nas estrelas: concretistas. E diante do mistério que tudo isto nos coloca, nós festejamos, sofremos, incorporamos. Mais uma vez a contradição nos abraça ao destruirmos, com tamanha velocidade, os povos indígenas diante de um discurso que se diz diverso. Que as universidades passem a se chamar diversidades.

A imposição da língua portuguesa em território brasileiro é das histórias de maior opressão linguística no mundo. À custa de muita repressão e ignorância. De Marques de Pombal à ditadura militar, a língua aqui sempre foi para o fomento da unidade, para a atividade senhoril e dominação de povos diferentes. Mas a diversidade ainda existe na paisagem denominada Brasil. Viva a contribuição milionária de todos os erros. Gramaticalizar os solos de todas as línguas que nomeiam nossas flores, disse o menino Manuel de Barros.

Qual é o Brasil que estamos vendo? Será possível dizer da origem do brasileiro? Quantas não são as origens, as possibilidades de surgimento de nossos povos que poderíamos assumir? E suas línguas? Como pergunta Silviano Santiago: onde usaremos o adjetivo brasileiro?
Jamais fomos modernos. Como diria Deleuze, trata-se de uma questão de saúde, de ecologia da terra, mas que precisa reinventar-se como forma de descolonização: "A saúde como literatura, como escrita, consiste em inventar um povo que falta." ${ }^{14}$ Uma saúde das relações sem história, sem idade ou modernidade, mística e concreta. Sábia, pois se transforma constantemente, criando comunidades. É convivendo, corpo a corpo, bioma por bioma, texto por texto, fragmento por fragmento, língua por língua, valorizando cada parte, sem a pretensão do todo e do uno, que se descarrilará a já formada literatura brasileira.

\section{REFERÊNCIAS}

ALMEIDA, Maria Inês de. Ensaios sobre a literatura indígena contemporânea no Brasil. Tese de doutorado inédita. São Paulo: PUC, 1999 .

ANDRADE, Oswald de. A utopia antropofágica. 2. ed. São Paulo: Globo, 1995

CANDIDO, Antonio. Formação da literatura brasileira: momento decisivos. 6. ed. Belo Horizonte: Itatiaia, 2000.

BARTHES, Roland. O prazer do texto. Trad. J. Guinsburg. São Paulo: Editora Perspectiva, 1973.

CAMPOS, Haroldo de. Pau Brasil: obras completas de Oswald de Andrade. São Paulo: Globo, 2002 
CASTRO, Eduardo Viveiros de. A inconstância da alma selvagem: e outros ensaios de antropologia. São Paulo: Cosac $\&$ Naify, 2002

CASTRO, Eduardo Viveiros de, Os pronomes cosmológicos e o Perspectivismo Ameríndio. Revista MANA, v. 2, n. 2, p. 115-144, 1996

DELEUZE, Gilles; GUATTARI, Félix. Mil platôs: capitalismo e esquizofrenia, vol. 1. Trad. Aurélia Guerra Neto e Célio Pinto Costa. São Paulo: Ed. 34, 1995.

DELEUZE, Gilles; GUATTARI, Félix. Mil platôs: capitalismo e esquizofrenia. vol. 4. Trad. Suely Rolnik. São Paulo: Ed. 34, 1997.

DELEUZE, Gilles; GUATTARI, Felix; GUIMARÃES, Julio Castanon. Kafka: por uma literatura menor. Rio de Janeiro: Imago, 1977

DELEUZE, Gilles. Crítica e clínica. Trad. Peter Pál Pelbart. São Paulo: Ed. 34, 1997.

\section{DERRIDA, Jacques. Essa estranha instituição chamada}

literatura. Trad. Marilene Dias. Belo Horizonte: Editora UFMG, 2014

KAXINAWÁ, Joaquim Paula de Lima et al. Shenipabu Miyui história dos antigos. Acre: Comissão Pró Índio, 1997

KEHIRI, Tõrãmü; PÃRÕKUMU, Umusí. Antes o mundo não existia: mitologia dos antigos Desana-Kêhíripõrã. Desenhos de Luiz e Feliciano Lana. 2. ed. São João Batista do Rio Tiquié: UNIRT: São Gabriel da Cachoeira: FOIRN, 1995.
HUGH-JONES, Sthephen. Escrita nas pedras, escrita no papel.

In: Palavras em imagens: escritas, corpos e memórias. Brasil; França, OpenEdition Press, 2016.

LIMA, Tânia Stolze Lima. Um peixe olhou pra mim: o povo Yudjá e a perspectiva. São Paulo: Editora UNESP; ISA; Rio de Janeiro: NuTI, 2005.

LLANSOL, Maria Gabriela. Falcão no punho. Diário I. Lisboa: Rolim, 1985

LLANSOL, Maria Gabriela. Lisboaleipzig I: O encontro inesperado do diverso. Lisboa: Rolim, 1994.

\section{MAXAKALI, Toninho et al. Cantos dos povos Morcego e}

Hemex-espíritos. Organização de Rosângela Pereira Tugny. Belo Horizonte: FALE/UFMG; Literaterras, 2013.

RISÉRIO, Antonio. Textos e tribos: poéticas extraocidentais nos trópicos brasileiros. Rio de Janeiro: Imago, 1993.

SANTIAGO, Silviano. Uma literatura nos trópicos: ensaios sobre dependência cultural. 2. ed. Rio de Janeiro: Rocco, 2000. 